\title{
The Effect of Total Quality Management on Service Quality in the Context of Services Based Small and Medium Enterprises of Pakistan
}

\author{
DR. SAIMA BATOOL \\ Chairperson and Assistant Professor \\ Qurtuba University of Science and Information Technology, Peshawar \\ dr.saimabatool90@yahoo.com \\ YASIR KHAN \\ Ph.D Scholar, Qurtuba University of Science and Information Technology, Peshawar \\ yasirok62@yahoo.com \\ MUHAMMAD TAHIR \\ Iqra National University, Peshawar, Pakistan. \\ tahirkhanzaee@gmail.com
}

\begin{abstract}
Pakistani economy is making a transition from strong manufacturing base to the services and in this scenario, service based small and medium enterprises (SMEs) are playing a major role. In current study, we focus on total quality management (TQM) which has the potential to enable the service based SMEs to improve their competitiveness in current highly dynamic environment. The objective of the study was to assess the current level of TQM implementation and its effects on the service quality in the context of service based SMEs of Pakistan. A survey was designed to collect primary data and the measures for TQM and service quality were adapted from previous sources. The study utilized quantitative approach and through stratified random sampling, data is collected from 135 participants belonged to the management of SMEs located in three cities of Pakistan. Our findings indicate that the dimensions of TQM including top management commitment, customer focus, people management, supplier quality management, continuous improvement, and the process management are only moderately followed by the Pakistani service based SMEs. In terms of effects, three out of six TQM dimensions are having positive and significant effects on the service quality and together these TQM dimensions explain up to $60.7 \%$ change in the dependent variable of service quality. Based on the findings, we recommend that service based SMEs should give more attention to the TQM implementation.
\end{abstract}

Keywords: Total Quality Management, Service Quality, Small and Medium Enterprises, Service Sector, Pakistan

\section{Introduction}

Pakistani economy is witnessing a significant change as in contrast to depending heavily on agriculture and textile manufacturing in the past, now services sector is 
making major contribution in the economy. In this new environment, service based small and medium (SMEs) are playing a vital role (Khawaja, 2006). The current study is focusing on the service based SMEs context and exploring the issue of total quality management and its effects on service quality.

\subsection{Background}

TQM is a managerial philosophy and is based on wide range of activities with the aim to improve the quality of products, services, and processes within the organization (Oakland, 2000). Initially, TQM is mostly adopted in the manufacturing sector; however, with the passage of time, the importance of TQM is realized by the service sector including the SMEs. In literature it is well established that TQM has positive effects for both manufacturing and services firm at International level and up to some extent in Pakistan(Mustafa, 2002; Rahman, 2001; Zhang 2000; Ahmed, 2000; Siddiqui, 2000; Manzoor, 2000; Huq \& Stolen, 1998). Mostly, the TQM studies conducted in Pakistan are in large scale manufacturing and only fewer studies conducted in the services sector with almost no study in the services based SMEs. Thus, the study is intended to fill this literature gap and enhance our understanding about the TQM, its implementation, and effects among the services based SMEs of Pakistan.

\subsection{Problem Statement}

Total Quality Management (TQM) is a managerial philosophy which encompasses all major aspects of an organization with the prime aim of improving the quality of products, processes, and so on. After its initial start in America and Europe, the TQM movement also gained momentum among the developing countries including Pakistan. Introduction of TQM in Pakistani manufacturing sector has produced mixed results; while, in Pakistani service based organization context, the TQM is facing at least three issues. The first issue is that there is little understanding and awareness about the TQM in this sector. Second the advantages of TQM in service based context are less understood. The third and final issue is that there is not much understanding about how TQM can be successfully implemented in SMEs context. The three issues are interrelated and is the prime focus of the current study.

\subsection{Significance of the Study}

The significance of the study is that it will fill the literature gap as the relationship between TQM and service quality is not studied in the service based SMEs of Pakistan. The findings of the study will be useful for the management of the service based SMEs about implementation and the benefit of TQM. The findings may also be beneficial for the practitioners and academics in the relevant field.

\subsection{Objectives of the Study}

Keeping in view the literature gap, the objective of this study are as follows.

- To identify that up to what extent the service based SMEs in Pakistan are applying the concept of TQM

- To see the effects of TQM on service quality among the service based SMEs of Pakistan

\section{Literature Review}

The literature review section discusses SMEs and their characteristics, TQM and its factors, Service quality and its dimensions, and the relationship between TQM and 
service quality.

\subsection{SMEs- A Brief Introduction}

The Small and Medium Size Enterprise Development Authority of Pakistan (SMEDA, 2017) defined small enterprise as the one which employs 10-35 employees and has productive assets of Rs. 2-20 million; while, the medium enterprise is the one which employs 36-99 employees and has productive assets of Rs. 20-40 million. There are other definitions of SMEs, however, in the current study, we will use the criteria as set in this definition for inclusion and data collection purpose. Certain common features of SMEs include the provision of capital by one or few individuals, limited resources, sole owner or partnership arrangement, limited human resource, high influence of owner's personality and competence on the success or failure of the firm, simple organizational structure, high informality, and less degree of sophistication in its processes and practices (Marri, Guna, Sekaran, \& Sohag, 2007; Julien, 1998).

\subsection{SMEs in Pakistan}

SMEs are considered vital for creating jobs and economic growth of a country (Ebrahim, Ahmed, \& Taha, 2009). In Pakistan, there are almost 3.2 million SMEs, which employ $90 \%$ of all enterprises in Pakistan and make $40 \%$ contribution in the total GDP of the country (SMEDA, 2017). Experts believe that there is a lot of potential for growth in Pakistani SMEs; however, these SMEs are unable to utilize their full potential due to limited support by the government and its institutions (Khawaja, 2006; Athar \& Aamir, 2004). Despite, the large number of SMEs which exist in Pakistan and the huge potential these SMEs possess, the government of Pakistan throughout the history gave little attention to the development of SMEs. The situation slightly improved in 1998, when government formed the 'Small and Medium Enterprise Development Authority' with a view to promote small and medium size businesses in Pakistan (KalSoft, 2004).More recently, the Government of Pakistan under the leadership of Prime Minister, Nawaz Sharif have initiated a major loan scheme. Under this scheme, micro-financingis provided to the youngsters with a low interest rate in order to help individuals to setup their own businesses. This action is also expected to boost the development of SME sector in Pakistan in upcoming years. Overall, it can be concluded that SMEs consist major portion of Pakistani economy and by boosting their potential, the whole Pakistani economy can benefit. One potential way of developing SMEs in Pakistan can be the application of total quality management (TQM). Its details are given in the following section.

\subsection{TQM Dimensions and SMEs}

Total quality management refers to the essential way of organization and involves the whole organization (Oakland, 2000). In current study, six key factors of TQM are utilized including top management commitment, customer focus, people management, supplier quality management, continuous improvement, and process management. Their relevance for SMEs is as under. Top management's commitment is the first factor and is about organization's top management to be committed towards quality, become role model, and make policies and take steps to implement quality. This aspect of SMEs is not very supportive for TQM mostly because of limited managerial skills and experience of owners and short term perspective adopted (Haksever, 1996; Ghobadian \& Gallear, 1996). Despite such limitations, SMEs can be very effective in implementing TQM as they got 
edge in terms of small size and direction reaction between employees, management, and customers (Ghobadian \& Gallear, 1996). Customer focus is another TQM factor which refers to the understanding of customer needs in a timely manner and then producing products and services accordingly. According to Haksever (1996), SMEs are in disadvantageous position as compare to larger organizations as due to limited resources, they are unable to collect very sophisticated data related to the customer needs. However, other experts such as Ghobadian and Gallear (1996) argues that since SMEs have close and direct interaction with customers; therefore, they are in advantageous position to easily understand and collect data related to customer needs. Effective people management is also an important factor of TQM and includes employees training and education, offering reasonable compensation system, and reasonable feedback mechanism. The HR function in most SMEs is also not very sophisticated (De Kok, 2003). For example, mostly SMEs offer very limited or no training along with informal and inadequate compensation to its employees (Ghobadian \& Gallear, 1996). Thus, the less use of sophisticated HRM practices put SMEs in disadvantageous position for TQM implementation.

Continuous improvement is another TQM factor which refers to the continuous monitoring of organization's processes and bringing improvements on incessant basis. The scarcity of resources in SMEs hinders the continuous improvement and its tools (Ghobadian \& Gallear, 1996). A counter argument can be that SMEs due to small size can be more adoptable and thus continuous improvement is easier in SMEs. Finally, process management is also a TQM factor which includes more hard aspects of TQM. Several sub activities such as house-keeping, benchmarking, and statistical techniques comes under the umbrella of process management. According to Ghobadian \& Gallear (1996), SMEs are unable to follow the process management due to limited resources and less managerial expertise. Overall, it can be conclude that TQM factors in SMEs are affected by limited resources, low management skills, short term thinking, informal system, and low attention towards quality.

\subsection{Service Quality}

Services are considered different from tangible products since they possess features which normal good do not possess. Due to the different nature of services as compare to the products, they are often evaluated by the customers in terms of service quality. Parasuraman, Valarie, \& Berry, (1985) defined service quality as a measure of how well the service level delivered matches the customer expectations. Service quality is measured by five dimensions based on the widely used SERVQUAL framework of Parasuraman, Zeithaml and Berry (1993). The framework consists of five dimensions including tangibility, reliability, responsiveness, assurance, and empathy. Tangibility refers to the physical aspects of service providers such as artifacts and buildings. Reliability refers to the ability to perform the promised services accordingly. Responsiveness refers to the willingness of service providers to help customer and prompt response such as telephone hotline and email system. Assurance refers to the ability of employees to foster trust and confidence among customers. Finally, empathy refers to the caring and personalized attention given to the customers. It is also referred to as understanding customer problem from customer perspective. Researcher's interest in 
the concept of 'service quality' is increased due to its association with cost reduction, increased customer loyalty, and higher profitability (Hallowell, 1996). Positive benefits of achieving service quality are also well established in literature. For example, Hallowell (1996) stated a positive association between customer satisfaction and the customer retention.

\subsection{Theoretical Framework}

The theoretical framework is based on the theory of TQM and the service quality. Literature on TQM establishes that TQM implementation has positive effects on general business performance and competitiveness (Zhang 2000; Huq \& Stolen, 1998; Ramesh, 1998).In Pakistani manufacturing based context, a study conducted by the Tahir, Batool, and Takrim (2016) found that implementation of TQM is positively associated with exports volume and its percentage in total sales among the small scale manufacturing organizations. The positive outcomes of TQM in services sector of Pakistan are also reported. Examples include a study conducted by Mustafa (2002) in a famous hospital; by Ahmed (2000) in a leading investment bank; by Siddiqui (2000) in a case study of a public sector organization; and Manzoor (2000) in a study of quality maintenance at Pakistan International Airlines. Overall, the positive outcomes of TQM are constantly reported in Pakistani service based organizations. For positive outcomes in the services based SMEs, we utilized the SERVQUAL framework for measuring service quality. The TQM is proposed to be related to the service quality since by following TQM principles; organization can standardize and improve the service quality which may lead to exceeding the customer's expectation. Therefore, in the light of literature and previous positive relationship between TQM and business outcomes, we propose that TQM has positive effects on the service quality. Consequently, we develop the following hypothesis;
$\boldsymbol{H}_{1}=$ Top management commitment is positively related to the service quality of service based SMEs of Pakistan
$\mathrm{H}_{2}=$ Customer focus is positively related to the service quality of service based SMEs of Pakistan
$\boldsymbol{H}_{3}=$ People Management is positively related to the service quality of service based SMEs of Pakistan
$\boldsymbol{H}_{4}=$ Supplier quality management is positively related to the service quality of service based SMEs of Pakistan
$\boldsymbol{H}_{5}=$ Continuous Improvement is positively related to the service quality of service based SMEs of Pakistan
$\boldsymbol{H}_{6}=$ Process management is positively related to the service quality of service based SMEs of Pakistan

\section{Research Methodology}

In social sciences, both quantitative and qualitative methods are used for answering research question or objectives. Quantitative methods are utilized when objective is to measure the degree of a phenomena already exist; while, the qualitative methods are suitable when objective is to explore and confirm the presence or absence of a particular phenomenon (Kirk \&Miller, 1986). Qualitative research involves different techniques such as case study and interview; while, quantitative method involves the use 
of statistical analysis to obtain findings (Marezyk, DeMatteo, \& Festinger, 2005). In this study, the quantitative approach is used keeping in view the nature and objectives of the study.

\subsection{Instrument and Data Collection Procedure}

Survey method is utilized in this study to collect data. The survey consisted of three parts where the first part of the instrument used to collect the demographic and organizational information. The second part of the survey was related to the TQM consisted of six dimensions measured by an instrument developed by Abusa (2011) and included 50 items. In this measure, top management commitment was measured by 9 items, customer focus by 10 items, people management by 12 items, supplier quality management by 6 items, process management by 6 items, and the continuous improvement was measured by 7 items. The third part of the survey was related to the service quality consisted of five dimensions measured by SERVQUAL model and adopted from Parasuraman, Zeithaml, and Berry (1993). In the service quality dimensions, tangible aspects were measured by 4 items, reliability by 5 items, responsiveness by 4 items, assurance by 4 items, and empathy is measured by 5 items. The responses for each statement or item were measured by Likert scale ranging from 1 as strongly disagree to 5 as strongly agree. Survey was distributed with the assistance of team consisted of three members located in each city.

\subsection{Population and Participants}

The population of the study is all service based SMEs in Pakistan; however, sample was drawn from the service based SMEs belonging to the three main cities including Islamabad, Lahore, and Peshawar. These three cities were chosen as they are key cities of Pakistan and mostly service based SMEs has presence in these major cities. A total of 295 questionnaires were distributed among the owners and management of service based SMEs. A total of 135 surveys were returned with the response rate of 45.7\%. The profile of the respondents given in the table 3.1 below:

Table 3.1: Demographic Profile of the Respondents

\begin{tabular}{|llcc|}
\hline & & Frequency & Percentage \\
\hline \multirow{4}{*}{ Gender } & Male & 103 & 76.3 \\
& Female & 32 & 23.7 \\
& 20-30 years & 21 & 15.6 \\
& 30.1-40 Years & 53 & 39.3 \\
\multirow{5}{*}{ Education Level } & 40.1-50 Years & 40 & 29.6 \\
& Above 50 Years & 21 & 15.6 \\
& Matric & 05 & 3.70 \\
& Intermediate & 24 & 17.8 \\
& Graduate & 63 & 46.6 \\
& Post Graduate & 43 & 31.9 \\
\hline
\end{tabular}

The demographic information given in the table 3.1 shows that the most respondents were male (76.3\%) while females participation was low (23.7\%). Similarly, most respondents had the age of between 30 to 40 years (39.3\%), followed by the age between 40 to 50 years (29.6\%). Most respondents were graduates or had the post 
graduate qualification (78.5\% combined for both categories). Besides the demographic profile of the respondents, the organizational profile of the respondents showed that all respondents belonged to the total of 42 services based SMEs located in three major cities of Pakistan.

\subsection{Reliability and Validity Issues}

Reliability and validity are two critical issues which a researcher need to address properly (Sekaran, 2003). For establishing validity of the measures adapted, the current study used face validity and content validity. For face validity, the instrument was presented to three university professors who agreed that mostly the instrument is valid and measuring the concepts as stated. The contentvalidity establishes that whether the indicator variables or dimensions of a construct adequately represent that latent construct. The content validity was established by matching the survey items with the literature on the topic and found consistent. The validity of the survey was also stable because both survey were adapted from previous well developed sources and have been applied in different research context. The reliability of the instrument was established by using the Cronbach alpha. All Cronbach alpha $(\alpha)$ were above the .60, therefore, the instruments can be considered reliable.

\subsection{Data Analysis}

The data was analyzed by descriptive statistics and the regression analysis. For running regression, its associated assumptions of normality of error term, no multicollinearity, homoscedasticity, and no autocorrelation were also tested.

\section{Results and Discussion}

The first objective of the study was to assess that up to what extent service based SMEs in Pakistan are applying the concept of TQM. For this purpose, the responses were aggregated and averages were taken on each dimension of TQM as well as on service quality. Descriptive statistics is given in the table 2 below.

Table 4.1: Descriptive Statistics on the Factors of TQM and Service Quality

\begin{tabular}{|lccccc|}
\hline & Minimum & Maximum & Mean & $\begin{array}{c}\text { Std. } \\
\text { Deviation }\end{array}$ & $\begin{array}{c}\text { Cronbach } \\
\text { Alpha }\end{array}$ \\
\hline Top Management & 1.44 & 4.56 & 3.4379 & .82801 & .898 \\
Commitment & 1.50 & 4.50 & 3.3815 & .73008 & .874 \\
$\begin{array}{l}\text { Customer Focus } \\
\text { People Management }\end{array}$ & 2.67 & 4.58 & 3.5685 & .47675 & .699 \\
$\begin{array}{l}\text { Suppliers } \\
\text { Management Quality }\end{array}$ & 2.17 & 5.00 & 3.7568 & .64735 & .772 \\
Continuous Improvement & 1.29 & 4.57 & 3.3598 & .76730 & .839 \\
Process Management & 2.17 & 4.83 & 3.5420 & .70995 & .771 \\
Tangible & 1.75 & 4.50 & 3.3019 & .71894 & .642 \\
Reliability & 2.00 & 5.00 & 3.6326 & .77506 & .806 \\
Responsiveness & 2.00 & 4.75 & 3.4778 & .74655 & .875 \\
Assurance & 1.75 & 4.50 & 3.5907 & .81646 & .826 \\
Empathy & 1.60 & 4.60 & 3.5644 & .75819 & .854 \\
Service Quality (Overall) & 1.95 & 4.32 & 3.5212 & .68367 & .949 \\
N=135 & & & & & \\
\hline
\end{tabular}


The descriptive statistics given in the table 4.1 and shows that most respondents only moderately agree that the TQM factors are implemented in their respective organizations. The results shows that in these organization, there is low to moderate degree of implementation of TQM factors including top management commitment (Mean=3.43, SD=.89), customer focus (Mean=3.38, $\mathrm{SD}=.73$ ), people management (Mean=3.56, SD=.47), suppliers quality management (Mean=3.75, SD=.64); and continuous improvement (Mean=3.35, SD=.76). The results on the elements of service quality also shows that in Pakistani SMEs based organizations, the perceived service quality is only at moderate level for tangibility (Mean=3.30, $\mathrm{SD}=.71$ ), reliability (Mean=3.63, $\mathrm{SD}=.77$ ), responsiveness (Mean=3.47, $\mathrm{SD}=.74$ ), assurance (Mean=3.59, $\mathrm{SD}=.81$ ), and empathy (Mean=3.56, $\mathrm{SD}=.75$ ). Further, the overall service quality is also slightly above the medium level $(\mathrm{M}=3.52, \mathrm{SD}=.68)$.

For analyzing the relationships between the variables and hypothesis testing, regression analysis was used. While running the regression, its assumptions were also tested. Normality of error term is determined by the histogram and NPP plot of residuals; multicollinearity issue is checked by the collinearity statistics and found within limits $(\mathrm{VIF}<2)$; homoscedasticity by the park test and found clear; and the no autocorrelation by the DW statistics which is also found close to the value of 2 (DWstat=2.21). Overall, the data is satisfying the assumptions of the regression analysis. Results are given in the table below.

Table 4.2: Regression Analysis

\begin{tabular}{|c|c|c|c|c|c|c|c|}
\hline \multirow[t]{2}{*}{ Model } & \multicolumn{2}{|c|}{ Unstandardized Coefficients } & \multirow{2}{*}{$\begin{array}{c}\text { Standardized } \\
\text { Coefficients } \\
\text { Beta }\end{array}$} & \multirow[t]{2}{*}{$\mathbf{t}$} & \multirow[t]{2}{*}{ Sig. } & \multicolumn{2}{|c|}{$\begin{array}{c}\text { Collinearity } \\
\text { Statistics }\end{array}$} \\
\hline & B & Std. Error & & & & Tolerance & VIF \\
\hline (Constant) & .315 & .314 & & 1.004 & .317 & & \\
\hline $\begin{array}{l}\text { Top } \\
\text { Management } \\
\text { Commitment }\end{array}$ & 196 & .056 & .238 & 3.485 & .001 & .659 & 1.518 \\
\hline $\begin{array}{l}\text { Customer } \\
\text { Focus }\end{array}$ & 240 & .068 & .257 & 3.515 & .001 & .575 & 1.740 \\
\hline $\begin{array}{l}\text { People } \\
\text { Management } \\
\text { Supplier }\end{array}$ & .110 & .097 & .077 & 1.138 & .257 & .673 & 1.486 \\
\hline $\begin{array}{l}\text { Quality } \\
\text { Management }\end{array}$ & -.028 & .071 & -.027 & -.394 & .694 & .678 & 1.474 \\
\hline $\begin{array}{l}\text { Continuous } \\
\text { Improvement }\end{array}$ & 297 & .069 & .333 & 4.282 & .000 & .508 & 1.970 \\
\hline $\begin{array}{l}\text { Process } \\
\text { Management }\end{array}$ & .122 & .076 & .127 & 1.620 & .108 & 493 & 1.983 \\
\hline $\mathrm{R}$ square & .607 & & & & & & \\
\hline Fstat (P Value) & $32.998(0.000)$ & & & & & & \\
\hline DW Stat & 2.213 & & & & & & \\
\hline
\end{tabular}

The results shows that on the dependent variable of service quality, top management commitment is having positive and significant effects $(\beta=196, \mathrm{P}<0.05)$; 
customer focus has positive and significant effects $(\beta=.240, \mathrm{P}<0.05)$; people management has positive but insignificant effects $(\beta=.110, \mathrm{P}>0.05)$; supplier quality management has negative and insignificant effects $(\beta=-.028, \mathrm{P}>0.05)$; continuous improvement has positive and significant effects $(\beta=.297, \mathrm{P}<0.05)$; and process management has positive but insignificant effects $(\beta=.122, \mathrm{P}>0.05)$. Further, the $\mathrm{R}$-square value shows that the dimensions of total quality management explain up to $60.7 \%$ change in the dependent variable of the service quality. The F-statistics suggest that overall model is fit and significant $($ Fstat $=32.99, \mathrm{P}<0.05)$. Based on these results, the hypothesis including $\mathrm{H} 1$, $\mathrm{H} 2$, and, H5, are accepted; while, H3, H4, and $\mathrm{H} 6$ are rejected.

\section{Discussion}

The objective of the study was twofold; first to assess that up to what extent the service based SMEs in Pakistan are applying the concept of TQM, and second, to see the effects of TQM on service quality. Data was collected from 135 respondents who belonged to the management of different service based SMEs located in three major cities of Pakistan. Data analysis shows that the service based SMEs in Pakistan are not applying the concept of TQM very well. Moreover, TQM is positively effecting the service quality of the service based SMEs. Thus, despite having positive effect of TQM, SMEs are not utilizing the concept very well which can be associated with different reasons. First, since most SMEs have limited resources (Westerberg, 1998); therefore, SMEs are unable to fulfill the TQM requirements such as investment in infrastructure and processes improvement along with long term human resource developmental approach. Other reasons of low implementation can be low understanding of owner about quality management, limited customer base and small profits, resistance towards change, and informal organizational structure and routines(Marri, Gunasekaran, \& Sohag, 2007; Bridge, ONeil, \& Cromie, 1998; Julien, 1998).Besides, the mentioned reasons, the institutional arrangement in Pakistan can also be a reason for low implementation of TQM in SMEs. Generally, in Pakistan, there is low degree of support from government or its supporting agencies for both SMEs and quality management (KalSoft, 2004); therefore, SMEs have to rely on their own capabilities and resources to implement TQM. The other part of the results which shows that TQM is having significantly positive effects on service quality is consistent with literature. The positive outcomes of TQM are found in numerous studies (Mustafa, 2002; Rahman, 2001; Zhang, 2000).

\subsection{Conclusion}

The findings of the current study shows that there is certainly room for improvement as service based Pakistani SMEs are not utilizing the concept of TQM very well. Moreover, the concept of TQM is also seems to be working in Pakistani SMEs and service based context and it is having a positive effect on the service quality level. Therefore, it can be concluded that if Pakistani service based SMEs apply the concept of $\mathrm{TQM}$, it can yield desirable outcomes such as increased service quality and competitiveness.

\subsection{Recommendations}

In the light of literature and the findings of the current study, the following recommendations are put forward.

- Service based SMEs should embrace the TQM concept and must put more efforts 
to improve the TQM implementation.

- The role of owners and managers is vital in TQM implementation; therefore, they must take responsibility for implementing quality management program in their respective organizations.

- Government of Pakistan should provide more assistance to the SMEs in order to enhance the understanding and implementation of the quality concepts. In this regard, special mentoring or educational programs should be arranged.

- Existing government institutions such as Small and Medium Enterprise Development Authority of Pakistan also need to take a more active role in order to educate and facilitate TQM implementation among SMEs.

- Universities should also play their role and must introduce TQM related courses and programs in order to improve the awareness and education of TQM. Moreover, more efforts should be directed towards contextual TQM related

\subsection{Limitations} research as it will further enhance the understanding of TQM in Pakistan.

A limitation of the study is that it only focused on six aspects of TQM while, other possible TQM dimensions, tools, and processes were not included in the study. The data on service quality is also taken on the perception by the management of the SMEs who may overstate it and thus introduce the bias. Furthermore, the sole focus on quantitative approach, small sample size, and survey measures which were not developed in Pakistani context are also major limitations of the study.

\section{References}

Abusa, F. (2011). TQM implementation and its impact on organizational performance in developing countries: a case study on Libya (Doctoral Thesis). Faculty of Engineering, University of Wollongong. http://ro.uow.edu.au/theses/3314

Ahmad, E.U. (2000). Case Study: Quality Improvement at Citibank N.A. Pakistan. Retrieved from www.piqc.com.pk/casestudies/services.

Athar, U., \&Aamir, K. (2004). Gallup Cyber letter on SME in Pakistan-2004.Retrieved from http://www.gallup.com.pk/News/SME_Apr_04.pdf

Bridge, S., O'Neill, K., \& Cromie, S. (1998).Understanding Enterprise, Entrepreneurship and Small Business. London; MacMillan Business.

De Kok, J.M.P.(2003).Human resource management within small and medium-sized enterprises, Rozenberg.

Ebrahim. N. A.., Ahmed, S., \&Taha, Z. (2009). Virtual R \& D teams in small and medium enterprises: A literature review.Scientific Research and Essays,4(13), 1575-1590

Ghobadian, A. \& Gallear, D. (1996). Total Quality Management in SMEs.Omega International Journal of Management Science, 24(1), 83-106.

Marri, H.B., Gunasekaran, A., Sohag, R.A. (2007). Implementation of advanced manufacturing technology in Pakistani small and medium enterprises: An empirical analysis. Journal of Enterprise Information Management, 20(6), 726 739.

Haksever, C. (1996). Total quality management in the small business environment. Business Horizons, 39(2), 33-41.

Hallowell, R. (1996). The relationship of customer satisfaction, customer loyalty and 
profitability; an empirical study. International Journal of Service Industry Management, 7(4), 27-42

Huq, Z., \& Stolen, J. (1998). Total quality management contrasts in manufacturing and service industries. International Journal of Quality \& Reliability Management, 15(2), 138-161.

Julien, P. A. (1998). The state of the art on small business and entrepreneurship. Aldershot: Ashgate Publishing Ltd.

KalSoft. (2004). Turn Potential into Profits: Business to Business Portal for Industrial Information Network - The Small and Medium Enterprise Development Authority, Case Study. $\quad$ Retrieved from http://www.ekalsoft.com/kalsoft/downloads/smeda.pdf

Khawaja, S. (2006). Unleashing the potential of the SME sector with a focus on productivity improvements. Paper presented at the Pakistan Development Forum.

Kirk, J., \& Miller, M. L. (1986). Reliability and validity in qualitative research. Beverly Hills, CA: Sage.

Manzoor, M. (2000). Aircraft Maintenance - Quality Cost to the Airline. Retrieved from www.piqc.com.pk/case studies/services

Marczyk, G., DeMatteo, D., \& Festiner, D. (2005). Essential of research design and methodology. New Jersey: John Wiley \& Sons.

Mustafa, R. (2002). Building Customer Satisfaction using Kano Model and QFD-A Pakistani Hospital Case Study. Retrieved from www.piqc.com.pk/case studies/services.

Oakland, J.S. (2000). Total Quality Management. Great Britain: Genesis Typesetting.

Parasuraman, A., Zeithaml V.A, \& Berry L.L. (1993). A multiple items scale for measuring consumer perceptions of service quality. Journal of Retailing, 66:1240

Parasuraman, A., Valarie, A., \& Berry, L. L. (1985). A Conceptual Model of Service Quality and Its Implications for Future Research. Journal of Marketing, 49 (Fall 1985), 41-50

Rahman, S. (2001). Total quality management practices and business outcome: evidence from small and medium enterprises in Western Australia. Total Quality Management, 12(2),201- 210.

Ramasesh, R. V. (1998).Baldrige Award announcement and shareholder wealth. International Journal of Qulity \& Reliability Management, 3(2), 114-25.

Sekaran, U. (2003).Research Methods for Business: A Skill Building Approach(4 edn.). New York: John Wiley \& Sons.

Siddiqui, A. R. (2000). PDCA at Work in Public Sector. Retrieved from www.piqc.com.pk/case studies/services

Small and Medium Enterprises Development Authority of Pakistan. (2017). State of SMEs in Pakistan. Retrieved from

http://www.smeda.org/index.php?option=com content\&view=article\&id=7:stat e-of-smes-inpakistan\&catid $=15$

Tahir, M., Batool, S., \& Takrim, K. (2016). The Effects of Total Quality Management on Exports in Manufacturing Based Small and Medium Enterprise's: A Case Study 
of Organizations from Selected Regions of Pakistan. NUML International Journal of Business \& Management, 11(1)173-197.

Zeithaml, V.A., Parasuraman, A. \& Berry, L.L. (1985). Problems and strategies in services Marketing. Journal of Marketing, 49, 33-46

Zhang, Z. (2000). Developing a model of quality management methods and evaluating their effects on business performance. Total Quality Management 11(1), 129-37. 